\title{
Psychological and psychosocial interventions for refugee children resettled in high-income countries
}

\author{
M. Fazel* \\ Department of Psychiatry, University of Oxford, Warneford Hospital, Oxford OX3 7JX, UK
}

Large numbers of refugee children are arriving in high-income countries. The evidence to date suggests that they have mental health needs that are higher than for the general population and that these are exacerbated by the numbers of traumatic events they have experienced and the post-migration stressors they continue to be exposed to. The importance of a thorough and thoughtful assessment is discussed. Treatments of note are described for post-traumatic stress disorder, family functioning, general mental health problems and school environments. Future opportunities to operationalise outcome measures, develop multimodal interventions and utilise implementation science methodology are considered.

First published online 10 November 2017

Key words: Refugee, children, intervention, PTSD, multi-modal.

\section{Introduction}

The causes that propel individuals into forced migration have been increasing across the globe - be that because of environmental degradation, natural disasters, global austerity and deepening poverty as well as organised violence. This latter precipitant is the focus of this issue, as in recent years, wars and civil unrest have contributed to the largest forced movement of people across the globe since World War II, predominantly as a result of unrest in the Middle East (UNHCR, 2017).

The mental health implications of forced migration for refugee children have been documented as higher than in host populations in a number of studies and reviews (Fazel et al. 2005; Jakobsen et al. 2014; Barghadouch et al. 2016a; Close et al. 2016). The prevalence of post-traumatic stress disorder (PTSD), anxiety and depressive disorders are in general higher than in host populations but there is significant heterogeneity given the dramatically different experiences these children might have had in their native countries as well as in their journey to and reception in a country of refuge (Reed et al. 2012). For example, prevalence rates of PTSD can range in studies from 10 to $25 \%$ in studies from high-income countries but have been as high as $75 \%$ in low- and middle-income country studies; and estimates of depression have ranged from 5 to $30 \%$ (Fazel et al. 2015). Furthermore, refugee children can arrive with primary caregivers, other family members or enter a high-income nation unaccompanied - either

\footnotetext{
* Address for correspondence: M. Fazel, Department of Psychiatry, University of Oxford, Warneford Hospital, Oxford OX3 7JX, UK.

(Email: Mina.fazel@psych.ox.ac.uk)
}

as a result of trafficking or other potentially fearsome journeys - all of which can contribute to very different mental health considerations.

The study, development and scrutiny of different interventions for refugee children is significantly impacted by the heterogeneity of refugee populations, as described above. This then effects opportunities to better systematise and interpret the available evidence as appropriate meta-analyses of interventions cannot be conducted. For example, studies can differ substantially in how populations are defined as refugees, what control group, if any, is chosen, the location of the intervention, the tools utilised to conduct any mental health measurements and their cross-cultural validity, the primary outcomes chosen, and finally aspects of the scope and intensity of the intervention itself.

Furthermore, there can be difficulties inherent in studying refugee populations because of cultural, environmental and political factors that can lead to greater mobility, numerous socio-economic needs, and immigration and residence insecurity. These, in combination with a poor conceptualisation of mental health presentations and services, add to the complexities of conducting systematic studies on these populations (Reed et al. 2012). This is further evidenced by the widespread underutilisation of mental health services by refugee children and their families (Colucci et al. 2014). It can thus be difficult to approach the field of intervention studies for refugee children in an integrated manner.

The prominent focus on treatments for PTSD (Cloitre, 2009; Nickerson et al. 2011; Eberle-Sejari et al. 2015; Nose et al. 2017) have dominated the majority of studies thus far conducted. Although PTSD is only one of a broad number of different presentations 
seen in refugee children, its study is possibly facilitated by a discrete diagnostic categorisation, often identified by specific events rather than the totality of the refugee experience, which might seem overwhelming. The data on interventions, therefore, are skewed towards treating PTSD. It is also an area of treatment that has, in children and across a range of potentially traumatic exposures, had positive results with moderate effect sizes observed across the different types and populations that have been traumatised. However, as the actual numbers participating in studies that can be compared remain small, there remains much to be done, especially given the substantial numbers of children currently forcibly displaced across the globe (Peltonen \& Punamaki, 2010).

A number of areas will now be considered. Firstly, the importance of a thorough assessment of the refugee child and their caregivers is discussed and then a range of encouraging interventions will be described.

\section{Importance of a thorough assessment}

The importance of an appropriate and thorough assessment that takes place in an accessible setting must necessitate any approach to identifying the best intervention that might be needed for a refugee child. This is because such a large proportion of refugee children do not access mental health services and those that do might not engage well with any determined treatment approach (Colucci et al. 2015; Barghadouch et al. 2016b). In order to best appreciate the factors that contribute to this, it is important to consider the many, often competing demands, placed on refugee children and their families such as their basic survival needs of food, housing, financial security and immigration determination. These needs are then coupled with the complexities of stigma that afflict all mental health interventions, especially for vulnerable populations. For refugee children and families, the concept of mental illness and services might be poorly understood; especially as such services are often poorly developed in many of the countries from which refugee populations have arrived.

The assessment of the refugee child needs to ensure that a full picture is drawn of their experiences across their life thus far, from what they might have experienced in their countries of origin, to their journeys to a country of refuge and then, in their current situation. The full extent of the psychological assessment has been described elsewhere, and includes assessment of their family, school and community as well as their full psychosocial needs (Fazel et al. 2015; $\mathrm{Ng}$ et al. 2016). The integrative model of adaptation and development after trauma and persecution (ADAPT) can guide a more tailored assessment as it proposes five core psychosocial pillars that are disrupted by trauma
- feeling safe and secure; bonds and attachments; a sense of fairness or justice; having a role and identity; and existential meaning (Silove, 2013).

Conducting a comprehensive neurodevelopmental and cognitive assessment can be particularly challenging in the context of cross-cultural differences in social behaviour in addition to the barriers that might be presented by assessments being conducted on a child who has only newly acquired the language (Kaplan et al. 2016; Ng et al. 2016). A recent systematic review of learning problems in refugee children highlighted a number of risk factors for learning problems (Graham et al. 2016). These included parental misunderstandings about educational styles and expectations, teacher stereotyping and low expectations, bullying and racial discrimination, pre-migration and post-migration trauma, and forced detention. Factors for success included high academic and life ambition, parental involvement in education, family cohesion and supportive home environment, accurate educational assessment and grade placement, teacher understanding of linguistic and cultural heritage, culturally appropriate school transition, supportive peer relationships and successful acculturation. These place an emphasis, therefore, on the role of key environmental actors - such as schools - to facilitate success. An assessment of the school and its environment, if the refugee child has been placed in school, is often essential in helping identify, assess and treat refugee children in need of mental health interventions (Tyrer \& Fazel, 2014; Fazel et al. 2016).

Review of a refugee child's physical health needs is important as this can be overlooked. It should include chronic health conditions, oral health and skin as well as questions about previous health, exposure to any infectious diseases endemic in countries of origin and transit, as well as physical injuries (Davidson et al. 2004; Gerritsen et al. 2006; Benson \& Smith, 2007). Previous head injury, especially if associated with loss of consciousness, is an important factor to ascertain as studies have demonstrated that this is highly prevalent in torture survivors and can have significant long-term neurodevelopmental and psychological effects including depression and PTSD (Mollica et al. 2002; Mollica et al. 2009; Keatley et al. 2013).

Finally, a sensitive assessment of violence exposure is needed. This is not only about previous exposures to torture and violence, which have consistently predicted longer term mental health needs, but also current exposures to violence within the child's home as well as community and school. Refugee families, in some studies, have been observed to have a higher rate of parent to child aggression (Pottie et al. 2015). This can be as a result of the complex interplay that might be experienced by refugee parents of deskilling 
on arrival in a new country, downward social mobility with lower socio-economic status than they had experienced previously and social isolation, all of which can then impact on the risk of maltreatment for children (LeBrun et al. 2016). A proposed cycle of violence highlights a potential sequence of events in which adults exposed to human rights violations are more prone to outbursts of excessive anger in the post-conflict environment with perceptions of enduring injustice playing an important role in perpetuating this cycle (Rees et al. 2011; Rees et al. 2013; Tay et al. 2015). The impact of exposure to continuing violence in the post-migration environment, either witnessed or experienced by the refugee child, needs therefore to be carefully considered and addressed.

The future might offer further assessment opportunities to identify higher risk populations, as highlighted by two recent studies looking at the potential role of genetic predisposition. These studies have demonstrated how variants of certain genes can increase susceptibility to mental health problems following trauma, such as the degree of MAOA expression in one study of Syrian refugees (Mulligan et al. 2017) and in another where carriers of a certain cortiocotropin-releasing hormone receptor 1 allele were more susceptible to mental health problems following trauma in both refugee and Dutch adolescents (Sleijpen et al. 2017).

\section{Treatments of note}

The study of interventions for refugee children can be framed under two main headings, those that are unimodal - directed at treating a specific disorder and comprise the majority of higher quality studies, or multimodal - those that are trying to address the many needs refugee children might present with in both their mental and physical health as well as their broader systems, be that in their family, school or wider community. Across high-income countries, a range of different interventions are offered, often with a limited evidence base. Many services offer no specific or targeted treatments, and those that do, primarily include enhanced services to treat individuals with PTSD. A small number of family-based and school-based interventions have also been offered (Tyrer \& Fazel, 2014). Many third sector and charitable organisations have arisen to meet the treatment gap by providing psychosocial interventions but few have been evaluated. A few innovative treatments of note are described below.

\section{PTSD and Narrative Exposure Therapy}

The evidence highlights how there are certain high-risk groups for PTSD and these include those who have experienced cumulative exposure to multiple types of torture, as well as post-migration instability such as many house moves, a lack of basic resources and immigration detention (Miller \& Rasmussen, 2010; Fazel et al. 2012).

The treatment of PTSD has been one of the more extensively studied areas, yet systematic reviews of adult literature often identify small numbers of highquality studies, and much less so for child populations (Eberle-Sejari et al. 2015; Brown et al. 2017; Morina et al. 2017; Nose et al. 2017). Narrative Exposure Therapy (NET) has the strongest evidence base thus far, a reflection of its consistent positive findings in adult and child studies and also the number of high-quality studies testing it (Neuner et al. 2008; Robjant \& Fazel, 2010; Ruf et al. 2010; Catani et al. 2012). NET holds promise as it is potentially scalable having been studied in lowresource settings with lay counsellors and, for mental health professionals, has a brief 2-day training. It has been developed to treat people who have suffered multiple traumatic experiences and chronologically explores each event in intricate detail to produce a life narrative. There is a need to replicate existing NET studies in more high-income settings, as well as test it against other treatment modalities of note - such as Eye-Movement Desensitisation and Reprocessing (EMDR) and Traumafocused CBT (TF-CBT). NET's adaptation for children, KIDNET, has been tested in at least seven studies mainly conducted in low- and middle-income countries (Neuner et al. 2008; Robjant \& Fazel, 2010; Ruf \& Schauer, 2012). It comprises approximately 6-10 sessions of around 90 min conducted at weekly intervals. The studies thus far conducted have demonstrated significant symptom reduction with sustained effects at follow-up of up to 12 months. Lay counsellors (including teachers) have been utilised in the studies in low- and middle-income settings, but how this would translate into high-income countries is still unclear but feasible given the success so far.

\section{Improving home environment, families and multimodal interventions}

There is a consensus that in the resettlement environment, positive psychosocial outcomes for youth and adults is significantly influenced by the integrity and functioning of families. Yet few intervention programs in mental health focus specifically on families in the refugee field. PTSD clusters in families (Sack et al. 1995) and can have negative effects on attachment and parenting (van Ee et al. 2016). An interesting model of participatory research based within two refugee communities in Boston demonstrates how developing interventions for refugee communities can take account of the needs that are identified by the refugee communities themselves. As a result of research to 
understand the problems, help-seeking behaviours and strengths to be fostered in each community, an intervention was developed with promising acceptability (Betancourt et al. 2010; Betancourt et al. 2015). This intervention includes ten modules delivered to caregivers and children in separate sessions and builds towards a family meeting to support understanding of previous and current stressors and foster more positive relationships.

\section{Facilitating better generic psychological treatment using a common elements approach}

Another method of treatment that is gaining increasing momentum and has interesting results are those that utilise a common elements treatment approach incorporating treatments for mood disorders, post-traumatic stress or anxiety problems. Lay workers have been trained to deliver a treatment intervention using a transdiagnostic approach for which early data showed a decrease in clinical symptoms and promising acceptability as determined by good retention in treatment (Murray et al. 2014). It has been piloted in the USA, Iraq and on the Thai-Myanmar border, although with little evidence to date for refugee children in highincome settings. Bolton has shown lay counsellors can effectively deliver interventions across disorders among trauma survivors (Bolton et al. 2014) as supported by a broader review of the use of paraprofessionals in treating PTSD in low-resource settings (Jain, 2010). Transdiagnostic protocols, which enlist a core set of elements to address a range of mental disorders, have emerging evidence of being as effective as disorder-specific treatments, and are potentially more scalable (Hersh et al. 2016; Michelson \& Patel, 2017).

In considering the practicalities of offering such intervention approaches to refugee children in highincome countries, it might be important to consider who might comprise a 'lay counsellor'; the training they might need as well as careful consideration of safeguarding and clinical governance issues. This term might apply to teachers, school assistants and other education staff as well as a range of mental health care workers who are without specific mental health qualifications but employed in third sector or voluntary organisations, and currently deliver a high proportion of community psychosocial interventions. More generic mental health services are starting to work collaboratively with 'lay workers' and community organisations to enhance engagement with more vulnerable hard-to-reach populations as well as improving experiences of and services offered by mental health services. This approach, therefore, holds promise for refugee children.
School-based interventions to improve mental health outcomes

There is emerging interest in the potential role that schools can play in providing mental health support and interventions, especially for vulnerable refugee populations such as unaccompanied minors as well as for families (Tyrer \& Fazel, 2014; Anders \& Christiansen, 2016; Fazel et al. 2016). Unimodal and multimodal interventions have been examined in schools and although the evidence base at present remains limited, it is growing and worthy of further enquiry. Interventions that have been trialled include targeted interventions to treat those with PTSD to interventions delivered in classrooms, often for newly arrived children. A range of interventions have been studied, with the greatest evidence base in those that focus on the verbal processing of previous traumatic events (Tyrer \& Fazel, 2014).

For example, a multi-tiered approach was used for a class of refugee children in a school in the USA, called Project SHIFA (Ellis et al. 2013). In this model, broad mental health promotion was offered to all, and those identified at higher risk were placed in school-based early intervention groups. Those with significant distress were given a direct trauma-based treatment under the trauma systems therapy (TST) model with more intense services including home-based mental health care, advocacy and case management. This model of treatment holds good promise, especially as it has engaged and utilised community resources. Future interventions can consider the whole school environment, as the interventions need not only be directed at refugee children but have the potential to focus on the whole community of learners at the school.

\section{Conclusions}

This focus on mental health interventions for refugee children in high-income settings does not negate the importance of appreciating the many strengths and capacities of refugee children and families arriving in high-income settings. However, in trying to ensure that those with mental health difficulties are able to access the best available interventions, it is important to appreciate the difficulties encountered in developing this field of research. In summary, the study of interventions for refugee populations has been hampered by difficulties with the heterogeneity of the populations studied and the limited number of highquality studies conducted - a reflection of populations where the research agenda can be difficult to prioritise, especially for children.

Of the many challenges in the field, three might be worthy of consideration for a more united approach. 
First is the prospect of minimising modifiable causes of heterogeneity across data in outcome studies. If a more unified approach could be adopted in outcome measures and validated data can be gathered from a narrowed band of instruments, then studies might be more amenable to meta-analysis and the pooling of information, which can substantially support the development of an evidence base of treatments for refugee children.

Secondly, given the complexity of issues that these populations often have to concurrently manage, more multimodal interventions that bring together interventions from different theoretical backgrounds and practices are needed to enhance the poorly developed current evidence base (Silverstone et al. 2016). For child refugee populations, multimodal interventions would potentially address components of the following: exposure to previous traumatic events; adjustment to new environments; linguistic and legal assistance; family and parenting support; and school-based interventions. These complex interventions can be harder to conceptualise, get funded and then be tested but given the global context of current need, these interventions need to be enhanced (Betancourt \& Chambers, 2016).

Finally, collaboration across health services and policy makers to embed an implementation science approach to any interventions developed are urgently needed to ensure that we can better elucidate the barriers and facilitators for successful implementation of interventions whilst also taking into consideration local contexts (Betancourt \& Chambers, 2016). A focus at the outset of intervention development on broader dissemination and identifying where an implementation strategy might facilitate making the intervention more successful and sustainable is needed. This is of heightened importance for the development of complex interventions across modalities to address the broad needs of refugee children (Kohn et al. 2001; Tabak et al. 2012). Incorporating the refugee and other stakeholder's views will also ensure that all relevant perspectives are understood and have been shown to assist with more successful long-term implementation (Craig et al. 2008; Curran et al. 2012; Tabak et al. 2012; Moore et al. 2015; Lucero et al. 2016).

The present opportunities to develop interventions for refugee children are more exciting than ever, given the advances that have taken place in conceptualising and testing complex interventions as well as the frameworks for developing sustainable and scalable interventions using implementation science methodology. If these are utilised well, the field has the potential to be propelled forward as such large numbers of forcibly displaced children are present across the globe - those under the age of 18 years comprise half of all refugee populations. Resettlement strategies that can address the difficulties of accessing refugee populations for informed study and enabling a more coherent research agenda that is aligned with public health and policy strategies are needed. With such large numbers arriving, the potential to learn from these populations, as well as understanding and addressing their mental health needs, have never been more auspicious.

\section{Conflicts of interest}

Mina Fazel declares no conflicts of interest.

\section{References}

Anders M, Christiansen H (2016). Unaccompanied refugee minors: a systematic review of psychological interventions. Kindheit und Entwicklung: Zeitschrift fur Klinische Kinderpsychologie 25, 216-230.

Barghadouch A, Carlsson J, Norredam M (2016a). Psychiatric disorders and predictors hereof among refugee children in early adulthood: a register-based Cohort study. Journal of Nervous and Mental Disease. doi: 10.1097/NMD. 0000000000000576.

Barghadouch A, Kristiansen M, Jervelund SS, Hjern A, Montgomery E, Norredam M (2016b). Refugee children have fewer contacts to psychiatric healthcare services: an analysis of a subset of refugee children compared to Danish-born peers. Social Psychiatry and Psychiatric Epidemiology 51, 1125-1136.

Benson J, Smith M (2007). Early health assessment of refugees. Australian Family Physician 36, 41-43.

Betancourt T, Chambers D (2016). Optimizing an era of global mental health implementation science. JAMA Psychiatry 73, 99-100.

Betancourt TS, Fawzi MK, Bruderlein C, Desmond C, Kim JY (2010). Children affected by HIV/AIDS: SAFE, a model for promoting their security, health, and development. Psychology Health \& Medicine 15, 243-265.

Betancourt TS, Frounfelker R, Mishra T, Hussein A, Falzarano R (2015). Addressing health disparities in the mental health of refugee children and adolescents through community-based participatory research: a study in 2 communities. American Journal of Public Health 105, S475-S482.

Bolton P, Lee C, Haroz EE, Murray L, Dorsey S, Robinson C, Ugueto AM, Bass J (2014). A transdiagnostic community-based mental health treatment for comorbid disorders: development and outcomes of a randomized controlled trial among Burmese refugees in Thailand. PLoS Medicine 11, e1001757.

Brown R, Witt A, Fegert J, Keller F, Rassenhofer M, Plener P (2017). Psychosocial interventions for children and adolescents after man-made and natural disasters: a meta-analysis and systematic review. Psychological Medicine 47, 1893-1905.

Catani C, Kohiladevy M, Ruf M, Schauer E, Elbert T, Neuner F (2012). Treating children traumatized by war and 
Tsunami: a comparison between exposure therapy and meditation-relaxation in North-East Sri Lanka. BMC Psychiatry 9, 22.

Cloitre M (2009). Effective psychotherapies for posttraumatic stress disorder: a review and critique. CNS Spectrums 14, 32-43.

Close C, Kouvonen A, Bosqui T, Patel K, O'Reilly D, Donnelly M (2016). The mental health and wellbeing of first generation migrants: a systematic-narrative review of reviews. Globalization and Health 12, 1-13.

Colucci E, Szwarc J, Minas H, Paxton G, Guerra C (2014). The utilisation of mental health services by children and young people from a refugee background: a systematic literature review. International Journal of Culture $\mathcal{E}$ Mental Health 7, 86-108.

Colucci E, Minas H, Szwarc J, Guerra C, Paxton G (2015). In or out? Barriers and facilitators to refugee-background young people accessing mental health services.

Transcultural Psychiatry 52, 766-790.

Craig P, Dieppe P, Macintyre S, Michie S, Nazareth I, Petticrew M (2008). Developing and evaluating complex interventions: the new Medical Research Council guidance. BMJ 337, a1655.

Curran GM, Bauer M, Mittman B, Pyne JM, Stetler C (2012). Effectiveness-implementation hybrid designs: combining elements of clinical effectiveness and implementation research to enhance public health impact. Medical Care 50, 217.

Davidson N, Skull S, Chaney G, Frydenberg A, Isaacs D, Kelly P, Lampropoulos B, Raman S, Silove D, Buttery J (2004). Comprehensive health assessment for newly arrived refugee children in Australia. Journal of Paediatrics and Child Health 40, 562-568.

Eberle-Sejari R, Nocon A, Rosner R (2015). Treatment of posttraumatic symptoms in child and adolescent refugees: a systematic review. Kindheit und Entwicklung: Zeitschrift fur Klinische Kinderpsychologie 24, 156-169.

Ellis B, Miller AB, Abdi S, Barrett C, Blood EA, Betancourt TS (2013). Multi-tier mental health program for refugee youth. Journal of Consulting and Clinical Psychology 81, 129-140.

Fazel M, Wheeler J, Danesh J (2005). Prevalence of serious mental disorder in 7000 refugees resettled in western countries: a systematic review. Lancet $\mathbf{3 6 5}$, 1309-1314.

Fazel M, Reed RV, Panter-Brick C, Stein A (2012). Mental health of displaced and refugee children resettled in high-income countries: risk and protective factors. Lancet 379, 266-282.

Fazel M, Reed R, Stein A (2015). Refugee, asylum-seeking and internally displaced children and adolescents. In Rutter's Child and Adolescent Psychiatry, $6^{\text {th }}$ edition (ed. A Thapar, DS Pine, JF Leckman, S Scott, MJ Snowling and E Taylor), Chap. 44, pp. 573-585. Wiley.

Fazel M, Garcia J, Stein A (2016). The right location? Experiences of refugee adolescents seen by school-based mental health services. Clinical Child Psychology $\mathcal{E}$ Psychiatry 21, 368-380.
Gerritsen AAM, Bramsen I, Devillé W, van Willigen LHM, Hovens JE, van der Ploeg HM (2006). Physical and mental health of Afghan, Iranian and Somali asylum seekers and refugees living in The Netherlands. Social Psychiatry and Psychiatric Epidemiology 41, 18-26.

Graham HR, Minhas RS, Paxton G (2016). Learning problems in children of refugee background: a systematic review. Pediatrics 137(6), e20153994.

Hersh J, Metz KL, Weisz JR (2016). New frontiers in transdiagnostic treatment: youth psychotherapy for internalizing and externalizing problems and disorders. International Journal of Cognitive Therapy 9(2), 140-155.

Jain S (2010). The role of paraprofessionals in providing treatment for posttraumatic stress disorder in low-resource communities. JAMA 304, 571-572.

Jakobsen M, Demott MA, Heir T (2014). Prevalence of psychiatric disorders among unaccompanied asylum-seeking adolescents in Norway. Clinical Practice Epidemiology \& Mental Health 10, 53-58.

Kaplan I, Stolk Y, Valibhoy M, Tucker A, Baker J (2016). Cognitive assessment of refugee children: effects of trauma and new language acquisition. Transcultural Psychiatry 53, 81-109.

Keatley E, Ashman T, Im B, Rasmussen A (2013). Self-reported head injury among refugee survivors of torture. Journal of Head Trauma \& Rehabilitation 28, E8-E13.

Kohn LT, Corrigan JM, Donaldson MS (2001). Crossing the Quality Chasm: A New Health System for the 21st Century. Committee on Quality of Health Care in America, Institute of Medicine: Washington, DC.

LeBrun A, Hassan G, Boivin M, Fraser SL, Dufour S, Lavergne C (2016). Review of child maltreatment in immigrant and refugee families. Canadian Journal of Public Health 106, eS45-eS56.

Lucero J, Wallerstein N, Duran B, Alegria M, Greene-Moton E, Israel B, Kastelic S, Magarati M, Oetzel J, Pearson C (2016). Development of a mixed methods investigation of process and outcomes of community-based participatory research. Journal of Mixed Methods Research 1, 20.

Michelson D, Patel V (2017). Commentary: distillation and element-based design of psychological treatments in global mental health - a commentary on Brown et al. (2017). Journal of Clinical Psychology and Psychiatry 58, 525-527. doi: 10.1111/jcpp.12714.

Miller KE, Rasmussen A (2010). War exposure, daily stressors, and mental health in conflict and post-conflict settings: bridging the divide between trauma-focused and psychosocial frameworks. Social Science \& Medicine 70, 7-16.

Mollica RF, Henderson DC, Tor S (2002). Psychiatric effects of traumatic brain injury events in Cambodian survivors of mass violence. British Journal of Psychiatry 181, 339-347.

Mollica RF, Lyoo IK, Chernoff MC, Bui HX, Lavelle J, Yoon SJ, Kim JE, Renshaw PF (2009). Brain structural abnormalities and mental health sequelae in South Vietnamese ex-political detainees who survived traumatic head injury and torture. Archives of General Psychiatry 66, 1221-1232. 
Moore GF, Audrey S, Barker M, Bond L, Bonell C, Hardeman W, Moore L, O'Cathain A, Tinati T, Wight D (2015). Process evaluation of complex interventions: Medical Research Council guidance. BMJ 350, h1258.

Morina N, Malek M, Nickerson A, Bryant RA (2017). Psychological interventions for post-traumatic stress disorder and depression in young survivors of mass violence in low- and middle-income countries: meta-analysis. British Journal of Psychiatry 210, 247-254.

Mulligan CJ, Clukay C, Quinlan J, Dajani R, Hamadmad D, Abudayyeh G, Panter-Brick C (2017). Genetics of risk and resilience in Syrian refugee youth. American Journal of Physical Anthropology 162, 294-295.

Murray L, Dorsey S, Haroz EE, Lee C, Aisiary M, Weiss W, Bolton P (2014). A common elements treatment approach for adult mental health problems in low-and middle-income countries. Cognitive and Behavioural Practice 21, 111-123.

Neuner F, Catani C, Ruf M, Schauer E, Schauer M, Elbert T (2008). Narrative Exposure Therapy for the treatment of traumatized children and adolescents (KidNET): from neurocognitive theory to field intervention. Child and Adolescent Psychiatric Clinics of North America 17, 641-664.

Ng LN, Cook AC, Thomas JT (2016). An evidence based framework for an initial needs assessment of unaccompanied minors. Archives of Disease in Childhood 101, A361.

Nickerson A, Bryant RA, Silove D, Steel Z (2011). A critical review of psychological treatments of posttraumatic stress disorder in refugees. Clinical Psychology Review 31, 399-417.

Nose M, Ballette F, Bighelli I, Turrini G, Purgato M, Tol W, Priebe S, Barbui C (2017). Psychosocial interventions for post-traumatic stress disorder in refugees and asylum seekers resettled in high-income countries: systematic review and meta-analysis. PLoS ONE 12(2), e0171030.

Peltonen K, Punamaki R-L (2010). Preventive interventions among children exposed to trauma of armed conflict: a literature review. Aggressive Behavior 36, 95-116.

Pottie K, Dahal G, Georgiades K, Premji K, Hassan G (2015). Do first generation immigrant adolescents face higher rates of bullying, violence and suicidal behaviours than do third generation and native born? Journal of Immigrant Minority Health 17, 1557-1566.

Reed RV, Fazel M, Jones L, Panter-Brick C, Stein A (2012). Mental health of displaced and refugee children resettled in low-income and middle-income countries: risk and protective factors. Lancet 379, 250-265.

Rees S, Silove D, Chey T, Ivancic L, Steel Z, Creamer M, Teesson M, Bryant R, McFarlane AC, Mills KL (2011). Lifetime prevalence of gender-based violence in women and the relationship with mental disorders and psychosocial function. Journal of the American Medical Association 306, 513-521.

Rees S, Silove DM, Tay K, Kareth M (2013). Human rights trauma and the mental health of West Papuan refugees resettled in Australia. Medical Journal of Australia 199, 280-283.

Robjant K, Fazel M (2010). The emerging evidence for Narrative Exposure Therapy: a review. Clinical Psychology Review 30, 1030-1039.

Ruf M, Schauer M (2012). Facing childhood trauma: Narrative Exposure Therapy within a cascade model of care. Chapter 9 in Murray. J Exposure Therapy: New Developments 229-261. Nova Science Publishers.

Ruf M, Schauer M, Neuner F, Catani C, Schauer E, Elbert T (2010). Narrative Exposure Therapy for 7- to 16-year-olds: a randomized controlled trial with traumatized refugee children. Journal of Traumatic Stress 23, 437-445.

Sack WH, Clarke GN, Seeley J (1995). Posttraumatic stress disorder across two generations of Cambodian refugees. Journal of the American Academy of Child and Adolescent Psychiatry 34, 1160-1166.

Silove D (2013). The ADAPT model: a conceptual framework for mental health and psychosocial programming in post conflict settings. Intervention 11, 237-248.

Silverstone P, Suen V, Ashton C, Hamza D, Martin E (2016). Are complex multimodal interventions the best treatments for mental health disorders in children and youth. Journal of Child and Adolescent Behaviour 4, 305.

Sleijpen M, Heitland I, Mooren T, Kleber RJ (2017). Resilience in refugee and Dutch adolescents: genetic variability in the corticotropin releasing hormone receptor 1. Personality and Individual Differences 111, 211-214.

Tabak RG, Khoong EC, Chambers DA, Brownson RC (2012). Bridging research and practice: models for dissemination and implementation research. American Journal of Preventive Medicine 43, 337-350.

Tay AK, Rees S, Chen J, Kareth M, Silove D (2015). Pathways from conflict-related trauma and ongoing adversity to posttraumatic stress disorder symptoms amongst West Papuan refugees: the mediating role of anxiety and panic-like symptoms. Comprehensive Psychiatry 63, 36-45.

Tyrer RA, Fazel M (2014). School and community-based interventions for refugee and asylum seeking children: a systematic review. PLoS ONE 9(2), e89359.

UNHCR (2017). Global trends. Forced Displacement in 2016. In Global Trends. The UN Refugee Agency: Geneva, Switzerland.

van Ee E, Kleber RJ, Jongmans MJ, Mooren TT, Out D (2016). Parental PTSD, adverse parenting and child attachment in a refugee sample. Attachment \& Human Development 18, 273-291. 